\title{
Assessing the Quality Measure for Follow-up Care After Children's Psychiatric Hospitalizations
}

Justin Blackburn, Pradeep Sharma, Kathryn Corvey, Michael A. Morrisey, Nir Menachemi, Bisakha Sen, Cathy Caldwell and David Becker

\begin{abstract}
Objective

Medicaid and Children's Health Insurance Program (CHIP) plans publicly report quality measures including follow-up care after psychiatric hospitalization. We aimed to understand failure to meet this measure, including measurement definitions and enrollee characteristics, while investigating how follow-up affects subsequent psychiatric hospitalizations and emergency department (ED) visits.
\end{abstract}

\section{Methods}

Administrative data representing Alabama's CHIP from 2013-2016 were used to identify qualifying psychiatric hospitalizations and follow-up care with a mental health provider within 7 and 30 days of discharge. Using relaxed measure definitions, follow-up care was extended to include visits at 45 to 60 days and visits to a primary care provider. Logit regressions estimated enrollee characteristics associated with follow-up care and, separately, the likelihood of subsequent psychiatric hospitalizations/ED visits within 30, 60, and 120 days.

\section{Results}

We observed 1,072 psychiatric hospitalizations during the study period. Of these, $356(33.2 \%)$ received follow-up within 7 days and 566 (52.8\%) within 30 days. Relaxed measure definitions captured minimal additional follow-up visits. The likelihood of follow-up was lower at both 7 (18 percentage points [pp], 95\% confidence interval [CI] -26 pp- $-10 \mathrm{pp})$ and 30 days (-26 pp, $95 \%$ CI $-35 \mathrm{pp}--17 \mathrm{pp})$ ) for hospitalization stays of $\geq 8$ days. Meeting the measure reduced the likelihood of subsequent psychiatric hospitalizations within 60 days by 3 pp (95\% CI -6 pp- -1 pp).

\section{Conclusions}

Among children, receipt of timely follow-up care after a psychiatric hospitalization is low, and not sensitive to measurement definitions. Follow-up care may reduce the need of future psychiatric hospitalizations/ED visits.

This is the author's manuscript of the article published in final edited form as:

Blackburn, J., Sharma, P., Corvey, K., Morrisey, M. A., Menachemi, N., Sen, B., Caldwell, C., \& Becker, D. (2019). Assessing the Quality Measure for Follow-up Care After Children's Psychiatric Hospitalizations. Hospital Pediatrics, 9(11), 834-843. https://doi.org/10.1542/hpeds.2019-0137 


\section{Introduction}

Psychiatric conditions including major depressive, bipolar, behavioral, and mood disorders are common among children and adolescents. Approximately $20 \%$ of children and adolescents in the United States have a psychiatric condition. ${ }^{1-3}$ Particularly concerning is that half of adolescents between ages 13-18 years will be treated for a psychiatric condition by the age of 18, including $22 \%$ with severe impairment. ${ }^{4}$ One condition alone, major depressive events with severe impairment, affected $9.4 \%$ of $12-17$ year old adolescents in 2017 , increasing $71 \%$ from $2007 .{ }^{5}$ Approximately $10 \%$ of hospitalizations and emergency department (ED) visits among children and adolescents have psychiatric primary diagnoses, approximately $20 \%$ of all hospitalizations have psychiatric comorbidities, and the evidence suggests prevalence and utilization are increasing. ${ }^{6-8}$ The direct and indirect costs to treat and manage these conditions is estimated over \$247 billion annually. ${ }^{2}$ Furthermore, psychiatric conditions are common among children with excessively high health expenditures, known as "super-utilizers."

Optimal management of psychiatric conditions is necessary for improving outcomes and reducing health care costs. Psychiatric readmissions and ED visits are most frequent within the first 30 to 90 days after an initial psychiatric hospitalization and may be associated with inadequate follow-up care. ${ }^{10-12}$ Ideally, all children acute psychiatric hospitalizations will receive appropriate counseling, attentive management of prescription medications, and timely follow-up care to ensure a successful transition back into the community. Medicaid and State Children's Health Insurance Program (CHIP) agencies voluntarily report compliance with this standard of care as part of the Centers for Medicare and Medicaid Services (CMS) Child Core Set. ${ }^{13}$ Specifically, Follow-Up After Hospitalization for Mental Illness (FUH), is a quality measure designed to identify 
the percentage of children who received follow-up care from a mental health provider within 7 and 30 days from discharge.

State-reported data demonstrates considerable variation in follow-up care after psychiatric hospitalization, ranging from $14.4 \%$ to $75.6 \%$ within 7 days and $28.7 \%$ to $91.0 \%$ within 30 days. ${ }^{14}$ Previous research associated follow-up care with age, race, geographic setting, and clinical conditions. ${ }^{15-17}$ However, prior studies have not examined whether poor measure performance is related to measure definitions or whether measure performance impacts acute downstream health service utilization.

Empirical evaluations of this quality measure are limited and therefore barriers to followup care, the existence of racial/geographic disparities, or the benefits are not well-characterized. The purpose of this study was to evaluate the measure FUH with three objectives. First, we described the components of the measure children most often fail to meet, including care received after 30 days from a someone other than a qualified mental health provider or at all. Second, we identified the characteristics of children associated with the likelihood of meeting the measure, including demographic, geographic, and hospitalizations characteristics. Finally, we assessed the extent to which subsequent hospitalizations and ED visits are associated with receipt of timely follow-up care.

\section{Methods}

\section{Data and Study Population}

This study used administrative data from Alabama's stand-alone CHIP, “ALL Kids,” from 2013 to 2016 to calculate the quality measure for follow-up after psychiatric hospitalizations. Throughout this time period, ALL Kids coverage was available in 12-month enrollment periods 
to Alabama children 18 years and younger with family incomes between $100 \%$ and $300 \%$ of the federal poverty level (FPL). Annual premiums and copayments for services are determined by family income as a percentage of FPL. This study was approved by an Institutional Review Board.

\section{Construction of the FUH Measure}

We constructed the FUH measure according to the CMS technical specifications manual. ${ }^{18}$ This measure is stewarded by the National Committee for Quality Assurance and uses Healthcare Effectiveness Data and Information Set (HEDIS) value set specifications for diagnosis and procedure codes, providers, and revenue center codes (i.e. what hospital department performed the procedure). First, to calculate the denominator for this measure, children aged 6 to 18 with a qualifying hospital discharge for acute psychiatric conditions were identified based on the HEDIS value set. Then, all non-acute inpatient stays (based on HEDIS value sets) were excluded. Next, eligibility was confirmed based on continuous enrollment for at least 30 days from discharge. Finally, exclusions were made for any transfers or readmissions within 30 days if those events were nonacute inpatient stays or non-psychiatric diagnoses. Per measure specifications, all readmissions and transfers for psychiatric diagnoses within 30 days were combined into single episodes. The numerator was calculated for a follow-up visit within 7 days and 30 days. Qualifying follow-up visits required specific procedure codes for care from a mental health provider or outpatient visits to specified types of behavioral healthcare settings determined from revenue center codes. 


\section{Variables}

Enrollee characteristics were derived from ALL Kids administrative systems. Eligibility categories based on FPL and race/ethnicity were identified from self-reported information provided by enrollee families on the enrollment application. Categories corresponding to cost sharing group included "low fee" between $146 \%$ to $156 \%$ FPL, "fee" between $157 \%$ to $208 \%$ FPL, and "expansion" between 209\% to 317\% FPL. A fourth group of children, the "no fee" group were exempted from cost-sharing by federal criteria, such as Native American heritage. We grouped enrollees into three mutually exclusive race/ethnic categories: white, black, and other. Two geographic measures were considered. First, rural-urban residence was based on ZIP code of enrollment address categorized into Rural-Urban Commuting Area (RUCA) codes. Second, to serve as a proxy variable for proximity to care, we constructed a measure of mental health provider density within 25 miles from an enrollee's residence and each provider's practice address using the geodetic distance from centroid to centroid.

To explore potential differences in follow-up related to unique characteristics of psychiatric conditions, index hospitalization primary diagnosis codes were combined into broader groupings of depression, mood disorders, behavioral disorders, bipolar disorder, psychosis, and an "other" category which included schizophrenia, autism, adjustment disorders, and all other diagnoses (appendix table 1). Length of stay for the index hospitalization was categorized as 0 to 3 days, 4 to 7 days, or 8 or more days.

To understand specific components of the measure that were challenging to achieve, we calculated the number of enrollees who would have met the measure under two different measure specifications holding the denominator constant. First, we examined the impact of extending the follow-up window to 45 - and 60-days post-discharge. Second, we recalculated the 30-day 
measure with primary care visits and any health care visits within 30 days of discharge. For primary care visits, we investigated whether some type of follow-up care with a child's primary care provider may have been substituted for measure-defined care (i.e. with a qualified mental health provider), which potentially could be a proxy measure of poor access to mental health providers. For the any health care visits, we considered any medical or dental claims (excluding pharmacy claims) paid during this time window to represent active use of health care services among enrollees.

Finally, we identified enrollees with hospitalizations and ED visits in the months subsequent the psychiatric hospitalization. Among enrollees in the measure denominator, we identified a subset with at least 30 days of continuous enrollment before their psychiatric hospitalization and at least 120 days following discharge. Within the 120 -day period, we identified psychiatric hospitalizations and ED visits consistent with HEDIS definitions and, separately, hospitalizations and ED visits for any reason. Comparison of this subset to the overall study population did not reveal substantive differences in any characteristics, however the subset on average was slightly older and of lower FPL (results available upon request). Given the magnitude of these differences, and adjustment for these characteristics in the models, we do not have evidence these differences resulted in biases affecting internal validity or generalizability.

\section{Statistical Analysis}

Bivariate comparisons of enrollee characteristics associated with receiving follow-up care were compared using $\chi^{2}$ tests. Multivariable comparisons were estimated with logit regression models controlling for all other characteristics. We report marginal 
effects at the means, which represent the percentage point change in the likelihood of the outcome for each predictor, holding all other factors constant at the mean value.

A sensitivity analysis was conducted to determine if a multi-level logit model was appropriate given the nesting of hospitalizations within hospitals. We observed 31 different hospitals, however $95 \%$ of discharges took place at 11 facilities. We recoded any hospital with less than $2.5 \%$ of observations into an "other" category representing $5 \%$ of observations. The multi-level modeling approach allowed us to partition the total variance in follow-up into individual and hospital-level components. From the intraclass correlation coefficient, hospitallevel variation explained just $3 \%$ of the total variation in follow-up within 7 days and $1 \%$ within 30 days. Coefficients from covariates were consistent with single-level logit models. Thus, we opted to report single-level logit models with hospital fixed effects (i.e. dummy variables) and clustered standard errors accounting for repeated visits among enrollees.

Separately, we estimated the association with meeting the follow-up measure at 30 days with the likelihood of having psychiatric hospitalizations or ED visits using logit regression with clustered standard errors to estimate marginal effects representing the percentage point change in likelihood, holding all other covariates constant at the mean.

\section{Results}

Between 2013 and 2016, 1,072 psychiatric hospitalizations among 866 enrollees met measure criteria for inclusion. Among those hospitalizations, 356 (33.2\%) received follow-up with a mental health provider within 7 days and $566(52.8 \%)$ within 30 days. The extension of time to 45 days or 60 days increased follow-up for 38 hospitalizations ( 3.5 percentage points) and 56 hospitalizations (5.2 percentage points), respectively. Among hospitalizations which 
otherwise had no qualifying follow-up care, an additional 8 (0.7 percentage points) had a primary care visit. and 172 (23.4 percentage points) used any services.

Characteristics of enrollees receiving follow-up within 7 days and 30 days are shown in Table 1. The second column from the left displays characteristics of all enrollees with psychiatric hospitalizations. Hospitalizations most commonly were among those aged $11-15$ years $(57.5 \%)$, female $(57.6 \%)$, white $(69.0 \%)$, urban $(71.4 \%)$, and had a depression diagnosis (49.0\%). The third column displays row percentages of enrollees who met the measure divided by the number of enrollees with that characteristic enabling comparison vis-à-vis overall follow-up proportion. Greater frequency of follow-up within 7 days was among females $(35.7 \%, p=0.05)$, other non-white/non-black race $(42.2 \%$, $\mathrm{p}=0.02)$, small rural residents $(43.5 \%, \mathrm{p}=0.05)$, primary diagnosis of depression $(39.1 \%$, $\mathrm{p}<0.001)$, and length of hospitalization $0-3$ days $(43.1 \%, \mathrm{p}<0.001)$. Lower frequency of follow-up within 7 days was among black race $(28.1 \%, \mathrm{p}=0.02)$, bipolar diagnosis $(20.7 \%, p=0.01)$, and length of hospitalization 8 or more days $(22.9 \%, p<0.001)$. Finally, the fifth column displays factors associated with follow-up within 30 days. Increased frequency of follow-up included being female $(55.9 \%, \mathrm{p}=0.02)$, primary diagnosis of depression $(58.5 \%, \mathrm{p}=<0.001)$, and length of hospitalization $0-3$ days $(63.6 \%, \mathrm{p}<0.001)$.

Individual characteristics associated with the likelihood of receiving follow-up care within 7 and 30 days estimated from logit models and controlling for all other covariates are shown in Table 2. The largest effects of reduced likelihood of follow-up within 7 days of discharge was observed for hospital length of stay, followed by age, and diagnosis. Hospital stays of 8 days or greater lowered the likelihood of follow-up by 18 percentage points relative to stays of 3 days or fewer $(\mathrm{p}<0.001)$. Children aged 11-15 
years were 13 percentage points less likely to receive follow-up compared to those 6-10 years old $(\mathrm{p}=0.03)$. Children with hospitalizations for mood disorders were 9 percentage points less likely to receive follow-up than children hospitalized for depression $(\mathrm{p}=0.02)$. The largest effects of increased likelihood of follow-up within 7 days was observed for hospitalizations in 2014 relative to 2013 ( 9 percentage points, $\mathrm{p}=0.03$ ). This was followed by the effect on children who identified as being non-white or non-black race/ethnicity compared to whites, which had an increased likelihood of 9 percentage points $(\mathrm{p}=0.02)$. Characteristics with statistically significant associations with the likelihood of follow-up within 30 days were fewer than observed for follow-up within 7 days, with only length of stay falling within conventional thresholds. Children hospitalized for 8 days or more were 26 percentage points less likely to receive followup within 30 days than with hospitalizations of 3 days or fewer $(p<0.001)$.

Among 745 index hospitalizations wherein enrollees had a minimum of 30 days continuous enrollment prior to admission and 120 days post-discharge, the proportion with subsequent ED and hospitalizations is shown in Table 3. The majority of hospitalizations were psychiatric. Enrollees with follow-up care had lower frequencies of subsequent hospital and ED utilization, although many differences were not statistically significant at conventional levels. A statistically significant association was observed for psychiatric hospitalizations within 60 days of discharge; $3.0 \%$ of enrollees with follow-up care were re-hospitalized compared to $6.0 \%$ without follow-up care $(\mathrm{p}=0.05)$.

The estimated likelihoods of subsequent ED visits are shown in Table 4, hospitalizations in Table 5. After controlling for all covariates, having follow-up care was associated with reduced likelihood of subsequent psychiatric hospitalizations and ED visits ranging between 2 
and 4 percentage points. However, statistical significance was not observed in the fully adjusted models.

\section{Discussion}

The receipt of timely follow-up care after psychiatric hospitalization is low. Based on measure specifications, approximately half of hospitalizations received qualifying follow-up care within 30 days of discharge. Prior studies have consistently observed lower-than-optimal rates of follow-up among individuals, but comparisons are difficult to interpret given differences in populations by age, diagnosis, health insurance coverage (i.e. Medicaid, private, etc), and inconsistent follow-up care specifications. ${ }^{10-12,14-17,19,20}$ National performance on this measure is highly variable and comparability across states and programs is difficult to ascertain. ${ }^{21,22}$ Differences between Medicaid and CHIP notwithstanding, some CHIPs report only on fee-for-service enrollees, while others include managed care or specific administrative subpopulations. Furthermore, while many states utilize External Quality Review Organizations, ${ }^{23}$ no single entity calculates performance across all state programs and therefore it is conceivable that differences in performance could be explained by interpretations of the measure, coding or billing practices, administrative subpopulation definitions, or other factors. We did not observe follow-up care sensitive to the measure definitions of timing or mental health provider criteria. Notably, we observed a sizeable proportion of enrollees without follow-up care who utilized services within 30 days of discharge, evidence they were active in the health system. A greater understanding of this subpopulation may elucidate barriers to follow-up care. 
Hospitalization length of stay was the only consistent factor associated with receipt of follow-up care within 7 and 30 days after controlling for covariates. Age and hospitalization primary diagnosis groups were associated only with follow-up in 7 days. We did not observe effects by hospital, provider density, geographic setting, cost-sharing strata, or race; all of which were hypothesized based on findings from other studies. ${ }^{10-12,14-17,19,20}$ However, differences could be attributable to studies focused only on adults, ${ }^{12,15}$ Medicaid recipients, ${ }^{16,19}$ ED visits (rather than hospitalizations), ${ }^{15}$ or disease-specific cohorts. ${ }^{17,20} \mathrm{We}$ also did not see large differences in performance over time, despite the growing national emphasis on quality measurement following the Children's Health Insurance Program Reauthorization Act of 2009 and release of the initial Child Core Set technical specifications in February 2011, just two years before the study period. ${ }^{24}$ Prior studies have noted differences in follow-up care based on diagnosis. Compared to hospitalizations for depression, we observed all other diagnoses received follow-up care less often. Depression diagnoses were the most common among all hospitalizations we observed, and the findings may reflect specific challenges of different conditions. Specifically, we observed depression hospitalizations tended to have shorter lengths of stay (results available upon request), while other diagnoses such as bipolar disorder and psychosis had longer durations. Additionally, because the HEDIS measure definition uses administrative claims data, it is not sensitive to characteristics of conditions, such as self-harm or suicidal behavior. This could influence follow-up both on the patient and provider side, consistent with the hypothesis that those with more severe illness are more likely to follow-up. ${ }^{20}$ However, we observed longer length of stay reduces the likelihood of follow-up, which may be counter-intuitive to the severity hypothesis and requiring of future investigation. For example, analyses with greater numbers of hospitalizations than we observed could parse out complex interactions between diagnosed 
conditions and the hospital length of stay. Likewise, more detailed information on disease characteristics/severity may enable a greater understanding of the unique challenges to follow-up care above and beyond diagnosis and the length of stay.

Although modest in the absolute effect size, there appears to be a consistent benefit of receiving timely follow-up care in the reduction of subsequent psychiatric hospitalization. We observed subsequent hospitalizations and ED visits for psychiatric conditions to occur infrequently; the observed risk was between $4.4 \%$ and $10.6 \%$ in our population. Follow-up care was associated with large relative effects - in the case of reducing psychiatric hospitalizations within 60 days, the relative difference was $50 \%$ lower for children with follow-up care. While timeliness is important to ensure patients are stabilized and have a successful transition home, reducing subsequent hospitalizations may also be an indicator of linkage to stable outpatient treatment, improved disease management, or more efficient use of health services. We observed fewer subsequent hospitalizations for enrollees receiving follow-up care but adjusting for covariates attenuated this association. Perhaps surprisingly, evidence in the scientific literature showing follow-up care has a demonstrable reduction in readmissions, subsequent hospitalizations, and ED visits is equivocal. While some studies of Medicaid recipients observed outpatient follow-up reduced psychiatric readmissions, ${ }^{11,12}$ a systematic review by Daniel et al ${ }^{25}$ did not find consistent evidence of a benefit of follow-up care and subsequent studies had similar conclusions. ${ }^{10,16,17}$ This counterintuitive observation may reflect variations in the quality followup care, or unmeasured disease severity. ${ }^{26}$ Repeated use of high acuity services, like hospitalizations and ED visits, for psychiatric care is a complex phenomenon, with many contributing demographic and clinical factors. ${ }^{27} \mathrm{~A}$ strong and consistent predictor of repeated hospitalizations and ED visits is having a prior psychiatric hospitalization or ED visit. ${ }^{27-29}$ Thus, 
follow-up care in the outpatient setting may reduce the reliance of the ED in the continuum of care for psychiatric care. ${ }^{28}$ Despite the modest associations between follow-up care and subsequent hospitalizations and ED visits, quality improvement efforts could aim to enhance the effectiveness of outpatient follow-up care. . Furthermore, challenges and gaps to measuring quality of care remain, particularly for psychiatric care. ${ }^{30-33}$ Our analyses highlight potential long-term effects (i.e. reduced psychiatric hospitalizations and ED visits) that routine measurement may miss. Thus, mental health quality measures should continue to be re-evaluated and continuously improved.

Our findings must be interpreted along with some limitations. Notably, the HEDIS measure we used is designed for administrative claims data, which is limited in the ability to capture all sociodemographic factors, including parent/caregiver decisions and/or other barriers to care. We attempted to address this limitation by controlling for multiple covariates, but unmeasured confounding is possible. Furthermore, administrative data cannot capture all potential benefits of follow-up care, such as qualitative assessment of "smooth transitions" or quality of life. Our study period coincided with the start of guidance from CMS to voluntarily track and report quality measures which are updated annually, and likewise coding/billing practices may have changed resulting in missing information about follow-up care. Finally, the generalizability beyond hospitalizations within Alabama's CHIP may be limited, particularly in states with greater or lesser availability of community-based mental health services/providers, or among children with different family income ranges. It is possible that factors associated with utilization may differ in other states than that observed in Alabama, as well as the outcomes associated with follow-up care. 


\section{Conclusions}

Opportunities to increase follow-up care after psychiatric hospitalizations exist within Alabama and nationally, as many states report low percentages. We did not observe follow-up rates sensitive to measurement definitions. We identified a limited influence by modifiable characteristics. While psychiatric conditions are complex and individual patients may present unique challenges, we observed conditions other than depression as well as longer length of stay associated with reduced follow-up, suggesting these patients are especially challenging. We observed a modest benefit of follow-up care in reducing subsequent psychiatric care utilization. 


\section{References}

1. Shaffer D, Fisher P, Dulcan MK, Davies M, Piacentini J, Schwab-Stone ME, Lahey BB, Bourdon K, Jensen PS, Bird HR, Canino G, Regier DA. The NIMH Diagnostic Interview Schedule for Children version 2.3 (DISC-2.3): description, acceptability, prevalence rates, and performance in the MECA study. Methods for the Epidemiology of Child and Adolescent Mental Disorders Study. J Am Acad Child Adolesc Psychiatry. 1996;35(7):865877

2. Perou R, Bitsko RH, Blumberg SJ, Pastor P, Ghandour RM, Gfroerer JC, Hedden SL, Crosby AE, Visser SN, Schieve LA, Parks SE, Hall JE, Brody D, Simile CM, Thompson WW, Baio J, Avenevoli S, Kogan MD, Huang LN; Centers for Disease Control and Prevention (CDC) Centers for Disease Control and Prevention. Mental health surveillance among childrenUnited States, 2005-2011. MMWR Suppl. 2013;62(2):1-35

3. Williams NJ, Scott L, Aarons GA. Prevalence of serious emotional disturbance among U.S. children: a meta-analysis. Psychiatr Serv. 2018;69(1):32-40

4. Merikangas KR, He J, Burstein M, Swanson SA, Avenevoli S, Cui L, Benjet C, Georgiades K, Swendsen J. Lifetime prevalence of mental disorders in U.S. adolescents: results from the National Comorbidity Survey Replication-Adolescent Supplement (NCS-A). J Am Acad Child Adolesc Psychiatry. 2010;49(10): 980-989

5. Center for Behavioral Health Statistics and Quality. Key Substance Use and Mental Health Indicators in the United States: Results From the 2015 National Survey on Drug Use and Health. Rockville, MD: Substance Abuse and Mental Health Services Administration; 2016

6. Bardach NS, Coker TR, Zima BT, Murphy JM, Knapp P, Richardson LP, Edwall G, Mangione-Smith R. Common and costly hospitalizations for pediatric mental health disorders. Pediatrics. 2014, 133(4): 602-609.

7. Kalb LG, Stapp EK, Ballard ED, Holingue C, Keefer A, Riley A. Trends in psychiatric emergency department visits among young and young adults in the US. Pediatrics. 2019;143(4):e20182192

8. Olfson M, Druss BG, Marcus SC. Trends in mental health care among children and adolescents. N Engl J Med. 2015;372(21):2029-38

9. Sen B, Blackburn J, Aswani MS, Morrisey MA, Becker DJ, Kilgore ML, Caldwell C, Sellers $\mathrm{C}$, Menachemi N. Health expenditure concentration and characteristics of high-cost enrollees in CHIP. Inquiry. 2016;53:1-8

10. Fontanella $\mathrm{C}$. The influence of clinical, treatment, and healthcare system characteristics on psychiatric readmission of adolescents. Am J Orthopsychiatry. 2008;78(2):187-198

11. James S, Charlemagne SJ, Gilman AB, Alema Q, Smith RL, Tharayil PR, Freeman K. Postdischarge services and psychiatric rehospitalization among children and youth. Adm Policy Ment Health. 2010;37:433-445

12. Nelson EA, Maruish ME, Axler JL. Effects of discharge planning and compliance with outpatient appointments on readmission rates. Psychiatr Serv. 2000;51(7):885-889

13. Mayhew M. 2019 Updates to the Child and Adult Core Health Care Quality Measurement Sets. Center for Medicaid and CHIP Services Informational Bulletin. November 20, 2018

14. Burwell SM. 2015 Annual Report on the Quality of Care for Children in Medicaid and CHIP. The Department of Health and Human Services. 2016

15. Carson NJ, Vesper A, Chen C, Le Cook B. Quality of follow-up after hospitalization for mental illness among patients from racial-ethnic minority groups. Psychiatr Serv. 2014;65(7):888-896 
16. Croake S, Brown JD, Miller D, Darter N, Patel MM, Liu J, Scholle SH. Follow-up care after emergency department visits for mental and substance use disorders among Medicaid beneficiaries. Psychiatr Serv. 2017;68(6):566-572

17. Fontanella CA, Hiance-Steelesmith DL, Bridge JA, Lester N, Sweeney HA, Hurst M, Campo JV. Factors associated with timely follow-up care after psychiatric hospitalization for youths with mood disorders. Psychiatr Serv. 2016;67(3):324-31

18. Centers for Medicare and Medicaid Services. Core Set of Children's Health Care Quality Measures for Medicaid and CHIP (Child Core Set) Technical Specifications and Resource Manual for Federal Fiscal Year 2018 Reporting: February 2018. Accessed September 3, 2018. URL: https:/www.medicaid.gov/medicaid/quality-of-care/downloads/medicaid-andchip-child-core-set-manual.pdf

19. Marino L, Wissow LS, Davis M, Abrams MT, Dixon LB, Slade EP. Predictors of outpatient mental health clinic follow-up after hospitalization among Medicaid-enrolled young adults. Early Interv Psychiatry. 2016;10(6):468-475

20. Yen S, Fuller AK, Solomon J, Spirito A. Follow-up treatment utilization by hospitalized suicidal adolescents. J Psychiatr Pract. 2014;20(5):353-362.

21. Centers for Medicare and Medicaid Services. Children's Health Care Quality Measures. Accessed on March 28, 2019. URL: https://www.medicaid.gov/medicaid/quality-ofcare/downloads/performance-measurement/performance-on-the-child-core-set-measures-ffy2016.zip

22. Centers for Medicare and Medicaid Services. Children's Health Care Quality Measures. Accessed on March 28, 2019. URL: https://www.medicaid.gov/medicaid/quality-ofcare/downloads/performance-measurement/performance-on-the-child-core-set-measures-ffy2017.zip

23. Medicaid and Children's Health Insurance Program (CHIP) Programs; Medicaid Managed Care, CHIP Delivered in Managed Care, and Revisions Related to Third Party Liability, 81 Fed. Reg. 27497 (May 6, 2016) (to be codified at 42 C.F.R. pts 431, 433, 438, 440, 457, 495)

24. The Department of Health and Human Services Children's Health Insurance Program Reauthorization Act Annual Report on the Quality of Care for Children in Medicaid and CHIP. September 2010. Accessed March 28, 2019. URL:

https://www.medicaid.gov/medicaid/quality-of-care/downloads/2010_secretary report.pdf

25. Daniel SS, Goldston DB, Harris AE, Kelley AE, Palmes GK. Review of literature on aftercare services among children and adolescents. Psychiatr Serv. 2004;55(8):901-912

26. Beadles CA, Ellis AR, Lichstein JC, Farley JF, Jackson CT, Morrissey JP, Domino ME. First outpatient follow-up after psychiatric hospitalization: does one size fit all? Psychiatr Serv. 2015;66:364-372

27. Leon SL, Cloutier P, Polihronis, et al. Child and adolescent mental health repeat visits to the emergency department: a systematic review. Hosp Pediatr. 2017;7(3): 177-186

28. Goldstein AB, Frosch E, Davarya S, et al. Factors associated with a six-month return to emergency services among child and adolescent psychiatric patients. Psychiatr Serv. 2007;58(11):1480-92

29. Sobolewski B, Richey L, Kowatch RA, et al. Mental health follow-up among adolescents with suicidal behaviors after emergency department discharge. Arch Suicide Res. 2013;17(4): 323-34. 
30. Blackburn J, Becker DJ, Morrisey MA, Kilgore ML, Sen B, Caldwell C, Menachemi N. An assessment of the CHIP/Medicaid quality measure for ADHD. Am J Manag Care. 2017;23(1): e1-e9

31. Menachemi N, Blackburn J, Becker DJ, Morrisey MA, Sen B, Caldwell C. Measuring prevention more broadly: an empirical assessment of CHIPRA Core Measures. Medicare Medicaid Res Rev. 2013;3(3)

32. Zima BT, Mangione-Smith R. Gaps in quality measures for child mental health care: an opportunity for a collaborative agenda. J Am Acad Chil Adolesc Psychiatry. 2001;50(8): 735737

33. Zima BT, Murphy JM, Scholle SH, Hoagwood KE, Sachdeva RC, Mangione-Smith R, Woods D, Kamin HS, Jellinek M. National quality measures for child mental health care: background, progress, and next steps. Pediatrics. 2013;131(S1):S38-49. 
Table 1. Enrollee characteristics and rates of follow-up after psychiatric hospitalization within 7 days and within 30 days $(\mathrm{N}=1,072)$

\begin{tabular}{|c|c|c|c|c|c|}
\hline & Cohort & $\begin{array}{c}\text { Follow-up } \\
\text { within } 7 \\
\text { days } \dagger\end{array}$ & p-value & $\begin{array}{c}\text { Follow-up } \\
\text { within } 30 \\
\text { days } \dagger\end{array}$ & $\begin{array}{c}\text { p- } \\
\text { value }\end{array}$ \\
\hline $\mathrm{N}(\%)$ & 1,072 & $356(33.2)$ & \multirow{3}{*}{0.41} & $566(52.8)$ & \multirow{3}{*}{0.64} \\
\hline Age $6-10$ years & $87(8.1)$ & $29(33.3)$ & & $46(52.9)$ & \\
\hline Age $11-15$ years & $616(57.5)$ & $195(31.7)$ & & $318(51.6)$ & \\
\hline Age 16-19 years & $369(34.4)$ & $132(35.8)$ & \multirow{3}{*}{0.05} & $202(54.7)$ & \multirow{3}{*}{0.02} \\
\hline Male & $455(42.4)$ & $136(29.9)$ & & $221(48.6)$ & \\
\hline Female & $617(57.6)$ & $220(35.7)$ & & $345(55.9)$ & \\
\hline White & $740(69.0)$ & $241(32.6)$ & \multirow{3}{*}{0.02} & $383(51.8)$ & \multirow{3}{*}{0.12} \\
\hline Black & $178(16.6)$ & $50(28.1)$ & & $90(50.6)$ & \\
\hline Other & $154(14.4)$ & $65(42.2)$ & & $93(60.4)$ & \\
\hline \multicolumn{6}{|l|}{ Cost-sharing Group } \\
\hline Low Fee & $323(30.1)$ & $115(35.6)$ & \multirow[t]{4}{*}{0.49} & $171(52.9)$ & \multirow[t]{4}{*}{0.81} \\
\hline Fee & $453(42.3)$ & $152(33.6)$ & & $245(54.1)$ & \\
\hline Expansion & $287(26.8)$ & $87(30.3)$ & & $146(50.9)$ & \\
\hline Exempt & $9(0.8)$ & $2(22.2)$ & & $4(44.4)$ & \\
\hline \multicolumn{6}{|c|}{ Rural-Urban Commuting Area } \\
\hline Urban & $765(71.4)$ & $243(31.8)$ & \multirow[t]{5}{*}{0.05} & $400(52.3)$ & \multirow[t]{5}{*}{0.21} \\
\hline Large Rural & $124(11.6)$ & $36(29.0)$ & & $61(49.2)$ & \\
\hline Small Rural & $115(10.7)$ & $50(43.5)$ & & $69(60.0)$ & \\
\hline Isolated & $65(6.1)$ & $25(38.5)$ & & $33(50.8)$ & \\
\hline Unknown & $3(0.3)$ & $2(66.7)$ & & $3(100.0)$ & \\
\hline \multicolumn{6}{|c|}{ Mental Health Providers within } \\
\hline \multicolumn{6}{|c|}{25 miles } \\
\hline $0-42$ & $277(25.8)$ & $89(32.1)$ & \multirow{4}{*}{0.27} & $135(48.7)$ & \multirow{4}{*}{.44} \\
\hline $43-108$ & $264(24.6)$ & $98(37.1)$ & & $146(55.3)$ & \\
\hline $109-232$ & $268(25.0)$ & $92(34.3)$ & & $145(54.1)$ & \\
\hline 233 or more & $263(24.5)$ & $77(29.3)$ & & $140(53.2)$ & \\
\hline \multicolumn{6}{|l|}{ Primary Diagnosis Group } \\
\hline Depression & $525(49.0)$ & $205(39.1)$ & $<0.001$ & $306(58.5)$ & $<0.001$ \\
\hline Mood Disorder & $196(18.3)$ & $55(18.3)$ & 0.09 & $96(49.0)$ & 0.24 \\
\hline Behavior Disorder & $149(13.9)$ & $41(27.5)$ & 0.11 & $71(47.7)$ & 0.18 \\
\hline Bipolar Disorder & $82(7.7)$ & $17(20.7)$ & 0.01 & $34(41.5)$ & 0.03 \\
\hline Adjustment Disorder & $44(4.1)$ & $14(31.8)$ & 0.84 & $22(50.0)$ & 0.70 \\
\hline Psychosis & $36(3.4)$ & $13(36.1)$ & 0.71 & $20(55.6)$ & 0.74 \\
\hline Other & $40(3.7)$ & $11(27.5)$ & 0.43 & $17(42.5)$ & 0.18 \\
\hline \multicolumn{6}{|l|}{ Hospital Length of Stay } \\
\hline $0-3$ days & $209(19.5)$ & $90(43.1)$ & \multirow[t]{3}{*}{$<0.001$} & $133(63.6)$ & \multirow[t]{3}{*}{$<0.001$} \\
\hline 4-7 days & $548(51.1)$ & $194(35.4)$ & & $322(58.8)$ & \\
\hline 8 or more days & $315(29.4)$ & $72(22.9)$ & & $111(35.2)$ & \\
\hline 2013 & $383(35.7)$ & $117(30.6)$ & \multirow[t]{4}{*}{0.09} & $205(53.5)$ & \multirow[t]{4}{*}{0.28} \\
\hline 2014 & $239(22.3)$ & $95(39.8)$ & & $137(57.3)$ & \\
\hline 2015 & $215(20.1)$ & $66(30.7)$ & & $109(50.7)$ & \\
\hline 2016 & $235(21.9)$ & $78(33.2)$ & & $115(48.9)$ & \\
\hline
\end{tabular}

Note: $\mathrm{p}$-value based on $\chi^{2}$ test.

$\dagger$ Row percentages shown in parentheses ( $n$ with characteristic who meet the measure / $n$ all with characteristic * 100 ), which is interpreted as rate of follow-up among those with that characteristic. 
Table 2. Adjusted likelihood meeting follow-up after psychiatric hospitalization measure at 7 and 30 days $(\mathrm{N}=1,072)$ for enrollee characteristics.

\begin{tabular}{|c|c|c|c|c|}
\hline & $\begin{array}{c}\text { Likelihood of } \\
\text { follow-up within } 7 \\
\text { days }\end{array}$ & p-value & $\begin{array}{c}\text { Likelihood of } \\
\text { follow-up within } 30 \\
\text { days }\end{array}$ & p-value \\
\hline Age 6-10 years & Reference & & Reference & \\
\hline Age $11-15$ years & $-0.13(-0.24,-0.01)$ & 0.03 & $-0.10(-0.21,0.01)$ & 0.07 \\
\hline Age $16-19$ years & $-0.09(-0.21,0.03)$ & 0.13 & $-0.07(-0.19,0.04)$ & 0.22 \\
\hline Female & $0.01(-0.05,0.07)$ & 0.67 & $0.03(-0.03,0.10)$ & 0.27 \\
\hline White & Reference & & Reference & \\
\hline Black & $-0.05(-0.12,0.02)$ & 0.19 & $-0.04(-0.12,0.04)$ & 0.31 \\
\hline Other & $0.09(0.01,0.17)$ & 0.02 & $0.08(-0.01,0.16)$ & 0.06 \\
\hline \multicolumn{5}{|l|}{ Cost-sharing Group } \\
\hline Low Fee & Reference & & Reference & \\
\hline Fee & $-0.05(-0.13,0.02)$ & 0.16 & $0.02(-0.06,0.09)$ & 0.66 \\
\hline Expansion & $-0.08(-0.16,0.01)$ & 0.06 & $-0.01(-0.09,0.08)$ & 0.95 \\
\hline Exempt & $-0.25(-0.46,-0.03)$ & 0.03 & $-0.18(-0.46,0.10)$ & 0.21 \\
\hline \multicolumn{5}{|l|}{ Rural-Urban Commuting } \\
\hline \multicolumn{5}{|l|}{ Code } \\
\hline Urban & Reference & & Reference & \\
\hline Large Rural & $-0.01(-0.10,0.09)$ & 0.99 & $0.03(-0.08,0.14)$ & 0.63 \\
\hline Small Rural & $0.09(-0.01,0.20)$ & 0.09 & $0.10(-0.01,0.21)$ & 0.07 \\
\hline Isolated & $0.09(-0.05,0.23)$ & 0.19 & $0.04(-0.10,0.18)$ & 0.56 \\
\hline \multicolumn{5}{|l|}{$\begin{array}{l}\text { Mental Health Providers } \\
\text { within } 25 \text { miles }\end{array}$} \\
\hline $0-42$ & Reference & & Reference & \\
\hline $43-108$ & $0.05(-0.04,0.13)$ & 0.27 & $0.06(-0.04,0.15)$ & 0.23 \\
\hline $109-232$ & $0.04(-0.06,0.14)$ & 0.43 & $0.07(-0.04,0.17)$ & 0.22 \\
\hline 233 or more & $-0.01(-0.11,0.09)$ & 0.79 & $0.07(-0.04,0.19)$ & 0.22 \\
\hline \multicolumn{5}{|l|}{ Primary Diagnosis Group } \\
\hline Depression & Reference & & Reference & \\
\hline Mood Disorder & $-0.09(-0.17,-0.01)$ & 0.02 & $-0.07(-0.16,0.01)$ & 0.08 \\
\hline Behavior Disorder & $-0.09(-0.19,-0.01)$ & 0.04 & $-0.07(-0.16,0.02)$ & 0.14 \\
\hline Bipolar Disorder & $-0.11(-0.23,0.01)$ & 0.07 & $-0.08(-0.19,0.04)$ & 0.20 \\
\hline Adjustment Disorder & $-0.03(-0.18,0.12)$ & 0.68 & $-0.02(-0.17,0.14)$ & 0.84 \\
\hline Psychosis & $0.07(-0.09,0.22)$ & 0.39 & $0.05(-0.11,0.21)$ & 0.56 \\
\hline Other & $-0.06(-0.20,0.08)$ & 0.43 & $-0.07(-0.23,0.09)$ & 0.37 \\
\hline \multicolumn{5}{|l|}{ Hospital Length of Stay } \\
\hline $0-3$ days & Reference & & Reference & \\
\hline 4-7 days & $-0.06(-0.14,0.02)$ & 0.15 & $-0.03(-0.11,0.05)$ & 0.50 \\
\hline 8 or more days & $-0.18(-0.26,-0.10)$ & $<0.001$ & $-0.26(-0.35,-0.17)$ & $<0.001$ \\
\hline 2013 & Reference & & Reference & \\
\hline 2014 & $0.09(0.01,0.17)$ & 0.03 & $0.03(-0.05,0.12)$ & 0.48 \\
\hline 2015 & $0.02(-0.06,0.10)$ & 0.69 & $-0.02(-0.11,0.07)$ & 0.70 \\
\hline 2016 & $0.04(-0.05,0.12)$ & 0.37 & $-0.04(-0.13,0.06)$ & 0.43 \\
\hline
\end{tabular}

Note: Estimates from logit regression, model also contains hospital fixed effects and standard errors are clustered to account for repeated observations within enrollees. 
Table 3. Subsequent hospitalizations and emergency department (ED) utilization 60, 90, and 120 days after index psychiatric hospitalization discharge, stratified by receipt of follow-up care within 30 days.

\begin{tabular}{|c|c|c|c|c|c|c|}
\hline & All $(\mathrm{N}=745)$ & $\begin{array}{c}\text { No follow- } \\
\text { up within } 30 \\
\text { days } \\
(\mathrm{n}=349)\end{array}$ & $\begin{array}{c}\text { Follow-up } \\
\text { within } 30 \\
\text { days } \\
(\mathrm{n}=396)\end{array}$ & $\begin{array}{l}\text { Absolute } \\
\text { Difference }\end{array}$ & $\begin{array}{l}\text { Relative } \\
\text { Difference }\end{array}$ & $\mathrm{p}$-value \\
\hline Psychiatric hospitalization within 60 days & $33(4.4 \%)$ & $21(6.0 \%)$ & $12(3.0 \%)$ & 3.0 & $50 \%$ & 0.05 \\
\hline Psychiatric hospitalization within 90 days & $55(7.4 \%)$ & $30(8.6 \%)$ & $25(6.3 \%)$ & 2.3 & $27 \%$ & 0.23 \\
\hline $\begin{array}{l}\text { Psychiatric hospitalization within } 120 \\
\text { days }\end{array}$ & $79(10.6 \%)$ & $45(12.9 \%)$ & $34(8.6 \%)$ & 4.3 & $33 \%$ & 0.06 \\
\hline Any hospitalization within 60 days & $35(4.7 \%)$ & $22(6.3 \%)$ & $13(3.3 \%)$ & 3.0 & $48 \%$ & 0.05 \\
\hline Any hospitalization within 90 days & $60(8.1 \%)$ & $32(9.2 \%)$ & $28(7.1 \%)$ & 2.1 & $23 \%$ & 0.29 \\
\hline Any hospitalization within 120 days & $85(11.4 \%)$ & $49(14.0 \%)$ & $36(9.1 \%)$ & 4.9 & $35 \%$ & 0.03 \\
\hline Psychiatric ED within 60 days & $39(5.2 \%)$ & $23(6.6 \%)$ & $16(4.0 \%)$ & 2.6 & $39 \%$ & 0.12 \\
\hline Psychiatric ED within 90 days & $52(7.0 \%)$ & $30(8.6 \%)$ & $22(5.6 \%)$ & 3.0 & $35 \%$ & 0.10 \\
\hline Psychiatric ED within 120 days & $67(9.0 \%)$ & $38(10.9 \%)$ & $29(7.3 \%)$ & 3.6 & $28 \%$ & 0.09 \\
\hline Any ED within 60 days & $93(12.5 \%)$ & $52(14.9 \%)$ & $41(10.4 \%)$ & 4.5 & $30 \%$ & 0.06 \\
\hline Any ED within 90 days & $136(18.3 \%)$ & $73(20.9 \%)$ & $63(15.9 \%)$ & 5.0 & $24 \%$ & 0.08 \\
\hline Any ED within 120 days & $169(22.7 \%)$ & $86(24.6 \%)$ & $83(22.7 \%)$ & 1.9 & $8 \%$ & 0.23 \\
\hline
\end{tabular}

Note: $p$-value based on $\chi^{2}$ test. Absolute differences are reported in percentage points, relative differences in percent change attributable to receiving follow-up care. 
Table 4. Likelihood of psychiatric hospitalizations visits 60, 90, and 120 days after index psychiatric hospitalization discharge $(\mathrm{N}=745)$ associated with receipt of follow-up care within 30 days, controlling for covariates.

\begin{tabular}{|c|c|c|c|c|c|c|}
\hline & \multicolumn{6}{|c|}{ Likelihood of Psychiatric Emergency Department Visit } \\
\hline & \multirow{2}{*}{$\begin{array}{l}\text { Within } 60 \text { days } \\
(95 \% \mathrm{CI})\end{array}$} & \multirow{2}{*}{\multicolumn{2}{|c|}{$\begin{array}{c}\text { Within } 90 \text { days } \\
\quad(95 \% \mathrm{CI})\end{array}$}} & \multicolumn{3}{|c|}{ Within 120 days } \\
\hline & & & & p-value & $(95 \% \mathrm{CI})$ & p-value \\
\hline Follow-up within 30 days & $-0.03(-0.06,0.01)$ & 0.11 & $-0.02(-0.05,0.02)$ & 0.46 & $-0.02(-0.07,0.02)$ & 0.32 \\
\hline Age $6-15$ years & Reference & & Reference & & Reference & \\
\hline Age $16-19$ years & $-0.01(-0.05,0.02)$ & 0.44 & $-0.01(-0.05,0.04)$ & 0.70 & $-0.03(-0.08,0.02)$ & 0.26 \\
\hline Female & $0.04(-0.01,0.08)$ & 0.08 & $0.01(-0.03,0.06)$ & 0.55 & $-0.03(-0.04,0.07)$ & 0.26 \\
\hline White & Reference & & Reference & & Reference & \\
\hline Black & $-0.01(-0.04,0.04)$ & 0.98 & $0.01(-0.05,0.06)$ & 0.74 & $0.01(-0.06,0.08)$ & 0.76 \\
\hline Other & $-0.01(-0.05,0.05)$ & 0.94 & $-0.02(-0.07,0.03)$ & 0.37 & $-0.03(-0.09,0.02)$ & 0.26 \\
\hline \multicolumn{7}{|l|}{ Cost-sharing Group } \\
\hline Low Fee & Reference & & Reference & & Reference & \\
\hline Fee & $-0.02(-0.06,0.02)$ & 0.27 & $-0.03(-0.09,0.03)$ & 0.325 & $-0.05(-0.12,0.02)$ & 0.21 \\
\hline Expansion & $-0.02(-0.07,0.03)$ & 0.39 & $-0.01(-0.07,0.05)$ & 0.69 & $-0.03(-0.11,0.04)$ & 0.41 \\
\hline Exempt & $0.12(-0.11,0.34)$ & 0.32 & $0.35(-0.01,0.71)$ & 0.06 & $0.33(-0.01,0.67)$ & 0.06 \\
\hline \multicolumn{7}{|l|}{ Rural-Urban Commuting } \\
\hline \multicolumn{7}{|l|}{ Area } \\
\hline Urban & Reference & & Reference & & Reference & \\
\hline Large Rural & $0.03(-0.03,0.09)$ & 0.30 & $0.05(-0.01,0.12)$ & 0.12 & $0.04(-0.05,0.12)$ & 0.37 \\
\hline Small Rural & $-0.01(-0.05,0.04)$ & 0.84 & $0.01(-0.06,0.07)$ & 0.85 & $-0.01(-0.08,0.05)$ & 0.68 \\
\hline Isolated & $-0.02(-0.06,0.03)$ & 0.50 & $0.04(-0.06,0.14)$ & 0.44 & $0.05(-0.06,0.16)$ & 0.38 \\
\hline \multicolumn{7}{|l|}{ Primary Diagnosis Group } \\
\hline Depression & Reference & & Reference & & Reference & \\
\hline Mood Disorder & $0.01(-0.04,0.06)$ & 0.72 & $-0.01(-0.07,0.06)$ & 0.85 & $-0.03(-0.10,0.05)$ & 0.49 \\
\hline Behavior Disorder & $0.01(-0.05,0.05)$ & 0.93 & $-0.01(-0.08,0.05)$ & 0.64 & $-0.02(-0.10,0.05)$ & 0.54 \\
\hline Bipolar Disorder & $0.02(-0.04,0.08)$ & 0.50 & $0.07(0.01,0.13)$ & 0.05 & $0.07(-0.01,0.15)$ & 0.07 \\
\hline Adjustment Disorder & $0.01(-0.10,0.10)$ & 0.98 & & & & \\
\hline Psychosis & $0.02(-0.07,0.11)$ & 0.62 & $0.04(-0.05,0.12)$ & 0.40 & $-0.01(-0.12,0.12)$ & 0.97 \\
\hline Other & $0.09(0.03,0.14)$ & $<0.01$ & $0.10(0.03,0.17)$ & 0.005 & $0.10(0.02,0.19)$ & 0.02 \\
\hline \multicolumn{7}{|l|}{ Hospital Length of Stay } \\
\hline $0-3$ days & Reference & & Reference & & Reference & \\
\hline 4-7 days & $-0.03(-0.08,0.03)$ & 0.31 & $-0.03(-0.08,0.03)$ & 0.38 & $-0.01(-0.07,0.05)$ & 0.80 \\
\hline 8 or more days & $-0.04(-0.10,0.02)$ & 0.23 & $-0.01(-0.07,0.06)$ & 0.88 & $0.02(-0.05,0.09)$ & 0.57 \\
\hline
\end{tabular}

Note: Models also control for year. Standard errors are clustered for repeated observations among enrollees. 
Table 5. Likelihood of psychiatric emergency department (ED) visits 60, 90, and 120 days after index psychiatric hospitalization discharge $(\mathrm{N}=745)$ associated with receipt of follow-up care within 30 days, controlling for covariates.

\begin{tabular}{|c|c|c|c|c|c|c|}
\hline & \multicolumn{6}{|c|}{ Likelihood of Psychiatric Hospitalization } \\
\hline & Within 60 days & p-value & Within 90 days & $\mathrm{p}$-value & Within 120 days & p-value \\
\hline Follow-up within 30 days & $-0.03(-0.07,0.01)$ & 0.11 & $-0.03(-0.07,0.01)$ & 0.14 & $-0.04(-0.08,0.01)$ & 0.11 \\
\hline Age $6-15$ years & Reference & & Reference & & Reference & \\
\hline Age $16-19$ years & $\begin{array}{c}-0.03(-0.06,- \\
0.01)\end{array}$ & 0.04 & $-0.01(-0.05,0.03)$ & 0.50 & $-0.01(-0.06,0.03)$ & 0.54 \\
\hline Female & $0.04(0.01,0.08)$ & 0.04 & $0.05(0.01,0.09)$ & 0.04 & $0.05(0.01,0.10)$ & 0.04 \\
\hline White & Reference & & Reference & & Reference & \\
\hline Black & $-0.01(-0.05,0.04)$ & 0.70 & $0.01(-0.05,0.06)$ & 0.79 & $0.01(-0.06,0.06)$ & 0.92 \\
\hline Other & $-0.02(-0.06,0.02)$ & 0.38 & $-0.01(-0.07,0.04)$ & 0.60 & $-0.03(-0.08,0.03)$ & 0.37 \\
\hline \multicolumn{7}{|l|}{ Cost-sharing Group } \\
\hline Low Fee & Reference & & Reference & & Reference & \\
\hline Fee & $-0.02(-0.07,0.03)$ & 0.37 & $-0.02(-0.07,0.03)$ & 0.38 & $-0.02(-0.08,0.03)$ & 0.41 \\
\hline Expansion & $-0.01(-0.07,0.04)$ & 0.58 & $0.01(-0.06,0.07)$ & 0.84 & $0.02(-0.05,0.09)$ & 0.63 \\
\hline Exempt & $0.38(-0.02,0.78)$ & 0.06 & $0.48(0.03,0.93)$ & 0.04 & $0.50(0.07,0.94)$ & 0.02 \\
\hline \multicolumn{7}{|l|}{ Rural-Urban Commuting } \\
\hline \multicolumn{7}{|l|}{ Area } \\
\hline Urban & Reference & & Reference & & Reference & \\
\hline Large Rural & $0.01(-0.05,0.08)$ & 0.66 & $0.02(-0.05,0.10)$ & 0.56 & $0.01(-0.06,0.09)$ & 0.73 \\
\hline Small Rural & $-0.03(-0.07,0.01)$ & 0.05 & $\begin{array}{c}-0.05(-0.09,- \\
0.01)\end{array}$ & 0.007 & $-0.07(-0.11,-0.03)$ & $<0.001$ \\
\hline Isolated & $0.01(-0.07,0.08)$ & 0.94 & $-0.02(-0.09,0.06)$ & 0.64 & $0.01(-0.10,0.13)$ & 0.86 \\
\hline \multicolumn{7}{|l|}{ Primary Diagnosis Group } \\
\hline Depression & Reference & & Reference & & Reference & \\
\hline Mood Disorder & $0.02(-0.03,0.06)$ & 0.40 & $-0.01(-0.05,0.05)$ & 0.94 & $-0.01(-0.07,0.04)$ & 0.72 \\
\hline Behavior Disorder & $0.01(-0.03,0.06)$ & 0.54 & $-0.01(-0.07,0.05)$ & 0.74 & $-0.04(-0.11,0.03)$ & 0.32 \\
\hline Bipolar Disorder & $0.01(-0.06,0.07)$ & 0.78 & $0.03(-0.04,0.10)$ & 0.43 & $0.05(-0.04,0.12)$ & 0.24 \\
\hline Adjustment Disorder & $0.03(-0.04,0.11)$ & 0.42 & $0.01(-0.09,0.10)$ & 0.938 & $0.05(-0.04,0.14)$ & 0.32 \\
\hline Psychosis & $0.01(-0.09,0.12)$ & 0.80 & $-0.02(-0.15,0.11)$ & 0.78 & $-0.05(-0.22,0.11)$ & 0.54 \\
\hline Other & $-0.01(-0.10,0.10)$ & 0.98 & $-0.04(-0.17,0.09)$ & 0.57 & $-0.07(-0.24,0.09)$ & 0.39 \\
\hline \multicolumn{7}{|l|}{ Hospital Length of Stay } \\
\hline $0-3$ days & Reference & & Reference & & Reference & \\
\hline 4-7 days & $-0.03(-0.08,0.02)$ & 0.27 & $-0.03(-0.04,0.06)$ & 0.33 & $-0.03(-0.09,0.03)$ & 0.33 \\
\hline 8 or more days & $-0.05(-0.11,0.01)$ & 0.08 & $-0.03(-0.10,0.03)$ & 0.31 & $-0.04(-0.11,0.03)$ & 0.25 \\
\hline
\end{tabular}

Note: Models also control for year. Standard errors are clustered for repeated observations among enrollees. 